\title{
Staying for Benefits: The Effect of a Health and Family Planning Program on Out-Migration Patterns in Bangladesh*
}

\author{
By Tania Barham ${ }^{\dagger}$ and Randall Kuhn
}

June 25, 2013

Keywords: health, family planning, migration, welfare magnetism, Bangladesh

\begin{abstract}
:
There is concern that government programs or development aid alter the pattern of domestic migration. We exploit the quasi-random placement of a health and family planning program in Bangladesh to examine if the program changed migration patterns between 1979-91. We find the flow of out-migration to domestic destinations was 19 percent lower in the treatment than the comparison area for men and women when program differences were largest. Due to return migration, program effects diminished and the stock of migrants living outside the study area was lower for women at 9 percent and there were no significant effects for men.
\end{abstract}

\footnotetext{
${ }^{*}$ We are grateful to Brian Cadena, Richard Jessor,Terra McKinnish, and Fernando Riosmena for their helpful comments, and Gisella Kagy for her research assistance. We thank Nizam Khan, Khairul Islam, Sajal Saha, and Abdur Razzaque for their help in preparing and understanding the Health and Demographic Surveillance data and Dr. Mohammad Yunus and Mr. J. Chakraborty for information on the rollout of the Matlab Maternal and Child Health and Family Planning program.

${ }^{\dagger}$ University of Colorado at Boulder, 483 UCB, Boulder, CO, 80309 (email: tania.barham@,colorado.edu; tel. 303492-0237).

* Global Health Affairs Program, Josef Korbel School of International Studies, University of Denver, $2201 \mathrm{~S}$. Gaylord St., Denver, CO 80208 (email: rkuhn@,du.edu; tel. 303-492-0621).
} 


\section{Introduction}

Internal migration flows are generally thought to be essential to the efficiency of national economies and there is concern that government programs or development aid alter this flow by changing the relative income between two areas. In particular, there has been a long debate in the US on the extent of welfare-induced migration and if high-benefit areas are "welfare magnets" (Cebula 1979; Moffit 1992). There is a similar concern in many developing countries, that targeted aid to rural areas may slow migration flow to more prosperous areas (Chen et al. 1998; NRC 2003). More generally, there is a need to understand what prevents the rural population from migrating to find better jobs (Ardington, Case, Hosegood 2009). Determining internal migration responses to benefit programs is clearly important but estimating the causal effect is challenging. Many government benefits are set federally so lack within-country variation to help deal with some of the endogeneity issues inherent in cross-country regressions. Where variation exists, it is usually not exogenous making it hard to find a good counterfactual group, leaving concerns that unobservables may be biasing results, or that benefit levels may be endogenously set. In addition, migration effects can be difficult to estimate since migration rates are often very low, sample sizes too small, or the data too aggregated to capture changes in migration (Moffit 1992; Gelbach 2004). As a result, rigorous research examining the migration response to programs that provide important cash or non-cash benefits is sparse.

This paper seeks to address this gap in the literature by taking advantage of the quasi-random placement of an important health intervention, The Matlab Maternal and Child Health and Family Planning (MCH-FP) program, in rural Bangladesh. We estimate the causal effect of this program on out-migration flows and stock. Program interventions included arguably some of the most important and widespread health interventions: family planning and the main childhood vaccines. This program was especially valuable to the local population because it provided access to services that were difficult to obtain through government services, such as vaccines. Previous research shows this program was effective and valuable to the beneficiaries as it had important effects on a number of dimensions of human capital accumulation including reductions in child mortality and fertility (Phillips et al. 1982, 1984; Koenig et al. 1990, 1991), and longterm improvements in cognitive functioning, height, and education (Barham 2012, Joshi and Schulz 2013). The program was phased-in starting with family planning in late 1977, followed by child health interventions in 1982, with many of the health interventions becaming available in the comparison area after 1988. This phasing-in provides us with three time periods in which to examine program effects: $1979-81,1983-88$, and 1989-91.

We benefit from unusually rich data from a Health and Demographic Surveillance System in the study site that regularly collects a variety of data including prospective observation on migration events. Using individual level data from 1979-91, we estimate the short-term intent-totreat program effects with age and year fixed-effects on the flow of out-migration from the area. The analysis focuses on women aged 25-44 and men aged 30-49 since they are more likely to benefit from program interventions and in order to focus on labor migration (rather than marriage migration). To estimate program effects on the annual flow of out migrants, we use a repeated cross section of individuals in the sample age range that lived in the study area prior to program start and have not died or already migrated out of the study area. We examine both domestic and international migration flow, though results mainly reflect domestic migration since international migration rates were low during this time period. 
To take into account that many of the out-migrants return to the study area, we also examine the effect of the program on the cumulative migrant stock, or the share of individuals present at program start living outside the area in a given year. To determine program effects on the stock of migrants, we follow a panel of individuals who were in the sample age range during the 197991 study period and who lived in the study area at the start of the program.

While the program is not randomly assigned, a comparison group was built into the design of the program so we can compare the change in migration between the treatment and comparisons areas for the three main time periods using a single difference estimator. We unfortunately lack adequate preprogram data to examine the baseline balance in migration between the two areas. So, to be conservative, we also use the $1979-81$ period, when only some of the program services were available, as a baseline to estimate double difference program effect for the latter two periods. In addition, we use pre-program data to show that the treatment and comparison group were similar with respect to most other characteristics at baseline.

We find the program did not lead to statistically significant differences in the flow or stock of out-migration between the treatment and comparison area in the 1979-81 period. But, during the 1983-88 period when all program interventions were available, the flow of out-migration was approximately 19 percent lower in the treatment compared to the comparison area for both women and men. However, the stock of migrants during this period was only lower for women, at about 9 percent. During the 1989-91 period, when government health services expanded, program effects were lower and generally not statistically significant. As a falsification test, we show there is no program effect on out migration flows for men aged 19-22 who were less likely to benefit from the program since few are married.

This paper adds to an important but sparse literature estimating causal effects of various types of benefit programs on migration patterns. For example, recent research on welfare migration in the US exploits differences in the generosity of cash welfare benefits across states in the United States. The research shows that the welfare migration effect on people most likely to benefit, single mothers without a high school degree, is fairly modest (Gelbach 2004, McKinnish $2005,2007) .{ }^{1}$ In developing countries, research examines the effect of randomized conditional cash transfer programs in Mexico and Nicaragua on behavioral responses including migration of older teens and prime age adults and find mixed results. In Mexico, the program led to a decrease or no impact on domestic migration but a small increase in international migration (Angelucci 2012; Stecklov et al. 2005), ${ }^{2}$ while in Nicaragua there was an increase in migration of males across a wide age range (Winters, Stecklov and Todd 2006). ${ }^{3}$ In related literature in South Africa, Ardington, Case, and Hosegood (2009) use longitudinal data to examine the effect of a household member gaining or losing an old-age pension on labor migration of prime age adults living in the same household. They find that an increase in household income leads to a small increase in labor migration, though they do not split this into domestic and international migration.

\footnotetext{
${ }^{1}$ For a review of the welfare migration literature prior to 1990s see Cebula (1979) and Moffitt (1992), for reviews of the more recent literature see Gelbach (2004) and McKinnish (2007).

${ }^{2}$ Angelucci (2012) examines heterogenous effects by preprogram predicted wages based on age and education for international migration but not domestic migration. Behrman, Parker, Todd (2009) also examines the effect of this program on migration, but focuses on longer-term effects on children ages 9-15 at baseline (ages 15-21 at follow-up) who benefit from the education component of the program.

${ }^{3}$ The different migration response in Nicaragua and Mexico could be due to a number of factors including differences in conditionalities, and that the Nicaragua economy was impacted by the coffee crisis at the time of the program.
} 
This paper has a number of advantages and makes several important contributions. First, we exploit a quasi-random experiment with treatment and comparison areas built into the design, and benefit from relatively large sample sizes and annual individual-level migration data so can address many of the methodological issues in the literature. Second, most research focuses on programs that provide cash-benefits, rather than direct service provision. Direct service programs are widespread in both developed and developing countries, and constitutes a greater share of expenditure than cash welfare programs in many countries, so are important to examine. Third, the long duration of our migration series allows us to measure the persistence of the treatmentcomparison migration differential throughout a long period to account for the tendency for return migration to diminish the out-migrant stock over time. Importantly, the examination of cumulative migrant stock provides insight into the extent of attrition bias that may be present in long-term program evaluations of similar programs. While the results are not externally valid beyond the study site, the program benefited people across socio-economic spectrum, so hopefully provide some insight into possible migration responses to similar health interventions among the poor in developed countries and those in other countries with similar levels of development.

The rest of the paper proceeds as follows. Section 2 provides a brief description of the MCHFP program and the mechanisms through which the program may affect migration; section 3 describes the data; section 4 explains the identification and estimation strategy; the findings and robustness analysis are discussed in section 5; and section 6 concludes.

\section{Background}

\subsection{The Matlab MCH-FP Program}

The MCH-FP program started in a rural area of Bangladesh, Matlab, in October 1977 and was implemented by the International Centre for Diarrhoeal Disease Research, Bangladesh (ICDDR,B). It started as a demonstration project to help the government design their national family planning program. Treatment and comparison areas were built into the design of the program and covered about 200,000 people in 149 villages with the population was split fairly evenly between the two areas (figure 1). The program included integrated family planning and maternal and child health $(\mathrm{MCH})$ services. Service delivery was intensive as interventions were administered in the house of the beneficiary during monthly visits made by local female health workers hired and trained by the program, and services were free of charge (Bhatia et al. 1980). Usual government health and family planning services were available in clinics in the area, but there was very limited or no home delivery. In addition, many of the program interventions, such as childhood vaccinations and the array of family planning options, only became readily available from the government after 1988 providing us with an experimental period between 1978-1988 to evaluate the program. Evaluation of the program is also aided by the rolling out of the program services over two main periods: $1977-81$ and 1982-88.

Program services prior to 1982 focused on family planning and maternal health through the provision of modern contraception, tetanus toxoid vaccinations for pregnant women, and iron and folic acid tablets for women in the last trimester of pregnancy (Bhatia et al. 1980). The health workers brought a wide-array of family planning options to the beneficiary's home including condoms, oral pills, vaginal foam tablets, and injectables. In addition, beneficiaries were informed about fertility control services provided by the project in health clinics such as intrauterine device insertion, tubectomy, and menstrual regulation. During these visits the female 
health workers also provided counseling on contraceptives, nutrition, hygiene, and breastfeeding, motivated women to continue using contraceptives, and instructed women how to prepare oral rehydration solution. These services were supported by well-developed follow-up and referral systems to ensure management of side effects and continued use of contraceptives (Phillips et al. 1984, Fauveau et al. 1994).

Between 1982-88, the types of interventions provided were expanded, especially for children under age five. These interventions were rolled out over time in the treatment area starting with the measles vaccine in half the treatment area in 1982. Starting in 1985, preventive services were provided to children under the age of five in the entire treatment area. These services included vaccines for measles, DPT, polio, and tuberculosis, and vitamin A supplementation. By 1988, coverage rates for children aged 12-23 months living in the treatment area were $93 \%$ for BCG, $83 \%$ for all three doses of DPT and polio, $88 \%$ for measles, and $77 \%$ for all three major immunizations (HDSS 2007). Curative care such as nutrition rehabilitation and acute care for respiratory infections was also introduced late in the period. In addition, the tetanus toxoid immunization was expanded to all women of reproductive age, and safe delivery kits were provided to pregnant women.

The program is still running today, but differences between the treatment area and the rest of the country, including the comparison area, diminished after 1988 as the lessons of the Matlab success were incorporated into the national plan (Phillips et al. 2003, Cleland et al. 1994). In particular, Bangladesh greatly increased the number of family welfare assistants to deliver inhome contraceptive and immunization services throughout the country. Expanding the number of family welfare assistants reduced the client-worker ratio from 1 per 8000 in 1987/88 to 1 per 5,000 in 1989/90 (Cleland et al. 2004). The ratio was still lower in the treatment area at 1 per 1,300 in $1990 .{ }^{4}$ Improvements in supply chains, products, and management were also rolled out in 1988 and 1989 (Cleland et al. 1994).

\subsection{Program Take-up}

Program implementation followed the planned timeline and uptake was rapid. For example, figure 2 shows that the contraceptive prevalence rate (CPR) for married women 15-49 was similarly low prior to the program $(<6$ percent $)$ in both the treatment and comparison area. There was a large increase in the CPR to 30 percent in the treatment area during the first year of the project. After that, there was a steady increase in the CPR with it reaching almost 50 percent by 1988. Due to availability of contraceptives from government services, the CPR did increase in the comparison area over time, but not as quickly, and rates remained below 20 percent in 1988. There was still a 20 percent difference in the CPR rate between the two areas in 1990.

As shown in figure 2, the measles vaccination rate rapidly increased after introduction to 60 percent in 1982 after it was introduced in the first half of the treatment area (treatment area 1), and in 1985 when it was introduced in the other half of the treatment area (treatment area 2). Vaccination rates in the comparison area are not available for this time period, but are believed to be near zero. Government services did not regularly provide the measles vaccine for children until around 1989 so the comparison area was viewed as largely an unvaccinated population (Koenig, Fauveau, and Wojtyniak 1991). Nationally, measles vaccination for children under the

\footnotetext{
${ }^{4}$ A direct comparison of the client-worker ratio between the areas is difficult because the health workers in the treatment area had more responsibilities, for example, the collection of regular demographic surveillance data. The national plan was based on cost-effectiveness analysis from other demonstration projects in Bangladesh (Phillips et al. 2003), so it is unclear how much difference there is in access to services based on the ratios alone.
} 
age of five was less than 2 percent in 1986 (Kahn and Yoder 1998), and was below 40 percent in the comparison area in 1990 (Fauveau 1994). As the national program scaled up, these differences narrowed substantially but not completely. According to data from the 1996 Matlab Health and Socioeconomic Survey, vaccination rates for children born in 1991 had reached 78\% for measles and $60 \%$ for $3^{\text {rd }}$ dose of DPT.

\subsection{Potential Effect of the MCH-FP Program and Migration}

Whether benefit programs such as government welfare programs or health services change migration patterns depends on a number of factors including how much the beneficiaries value the program, specifics of the program including if it requires physical presence, and the mechanisms that drive migration. We focus on understanding the potential short-term effects of the program on adult labor migration. We do not consider possible longer-run effects of the program on the labor migration of the children who benefited from the child health interventions or smaller family sizes.

Based on the description of the program interventions in section 2.1, the individuals or families most likely to value or benefit from the MCH-FP program are more likely to be married (since pre-martial sexual activity is rare among women), in need of on-going family planning services or maternal care, and have children under the age of five. In addition, given restrictions on women's mobility within this society, females may also value the social contact provided by the health worker's monthly visit. With the exception of a few contraceptive methods, program services were almost exclusively for women and children under age five. So, adult males did not directly receive many services, though indirectly benefitted from their spouse's use of the services. Unmarried adult males were even less likely to directly or indirectly benefit from the services so would value them less. ${ }^{5}$

Program services were place based, so to receive the interventions beneficiaries needed to be at their house during the monthly visit. If a family was only interested in, or in need of preventive services, the individual could conceivably migrate and return roughly 4 times a year to receive the services in their original treatment household (if the household still existed). This is because modern contraception included injectables and pill supplies that provided 3-6 months of protection, the vaccine schedule for children above the age of one probably only required vaccination once a year, and vitamin A supplementation is recommended every 4 to 6 months. (Fauveau 1994, Rahman et al. 1980). For those who returned within a six-month period, they would not be considered a migrant.

Standard models of migration provide insight into how the MCH-FP program may affect family migration. In particular, these models suggest that migration occurs when the expected income in the destination origin is higher than the expected income from staying in the point of origin plus the cost of migration. (Sjaastad 1962, Harris and Todaro 1970). Expected income depends on a number of individual characteristics including age and skill. However, this model can be generalized to consider expected utility or welfare, rather than just income, which in the context of this paper would include access to certain types of health care services. Therefore, given that in order to benefit from the MCH-FP program the beneficiary family needs to be present in the home in the treatment area for the health care visits, beneficiary families who value the MCH-FP program will have an incentive to reduce their migration relative to those in

\footnotetext{
${ }^{5}$ Unmarried men may have some future value for the program when they marry or because they may be able to find a higher quality bride if they live in the treatment area. In addition, if they lived in a household with beneficiaries, may value living in a healthier household with perhaps less children or longer birth spaces between children.
} 
the comparison area.

A more recent literature recognizes that migration may be a joint family decision where family members may strategically migrate in order to diversify earnings risk for the whole family allowing temporary and return migration (Stark and Bloom 1985, Stark and Levhari 1982). In societies where families do not have to migrate as a unit, a household may share the cost and benefits of migration of certain family members. In Bangladesh, solo male labor migration after marriage is possible. Most of this migration is temporary as men often return home during the harvest season and many eventually permanently return to the point of origin (Kuhn, 2003, 2011). So, program effects may differ for men and women, either in the tendency to migrate or in the tendency to remain in the destination.

\subsection{Potential Confounder: The Meghna-Dhonnogoda Irrigation Project}

One potential confounding factor affecting migration decisions relates to the construction of a river embankment in the study area. In 1987, the Government of Bangladesh completed construction of the Meghna-Dhonnogoda Irrigation Project, a flood control embankment and irrigation project that was constructed where the northern bank of the major Meghna River meets the west bank of the smaller Dhonnogoda River, which runs through Matlab (see figure 1). Mobarak, Kuhn and Peters (2013) demonstrate that the embankment project affected household productivity and marriage patterns, but did not affect marriage migration (either internally or externally from Matlab). Strong and Minkin (1992) observed no significant changes in outmigration after the construction of the embankment for protected or unprotected areas.

Neither of these studies looked specifically at those unprotected villages that were situated along the Meghna River, sitting between the river and embankment, which we refer to as the "Meghna area" on figure 1. These villages were all located in the comparison areas and the embankment had two important consequences for these villages. First, seven villages in this area that lined the river (referred to as "erosion villages") were partially or fully inundated as part of the embankment project between 1984 and 1986. All households in these villages were displaced, with most initially relocating to adjoining villages within the comparison area. Second, due to the size and strength of the Meghna River, the embankment was repositioned mid-project to a more stable position further from the river, so there are a number of villages in the Meghna area (referred to as "Meghna villages") that are unprotected and are more likely to suffer from flooding since they are between the river and the embankment. Indeed, there were major floods on this river in 1987 and 1988. Migration rates were slightly higher in general in these two areas prior to the embankment project due to more frequent flooding.

To control for this higher migration in the Meghna area in general, we include two indicator variables in all regressions indicating if a person lived prior to the start of the MCH-FP program in a village that was submerged as a result of the project ("erosion village") or in a village that was not submerged but between the Meghna river and the embankment.

To control for the effect of the embankment and the destruction of some of the villages when it was created, we include a series of variables that we refer to in the tables as embankment controls. First, since the "erosion villages" were submerged in 1984 and 1985, we include indicator variables if the current residence is an "erosion village" in these two years, even if the person migrated-out in that year. In addition, as a robustness check we drop all people who have lived in an erosion village since 1977. Second, we include separate indicator variables for the years 1986 to 1991 if the current residence is unprotected by the embankment. Data on embankment protection status comes from a study conducted by ICDDR,B (Strong and Minkin 
1992). We include dummies for each year since the embankment was completed and one year prior to its completion. We also include separate indicator variables for 1986-1991 for the unprotected villages in the Meghna area to allow there to be a differential embankment effect among these villages.

\section{Data}

This paper benefits from rich data available on the entire study site (i.e. the treatment and comparison areas) and the ability to link the different data sources together by individual or household identifiers. In particular, we link annual individual-level migration data from the Matlab Health and Demographic Surveillance System with individual- and household-level censuses data on the study site for various years using individual level identifiers. These data sources are available from ICDDR,B. Using these data, we construct two yearly individual-level dataset from 1979-91 to examine out-migration flows the stock. We do not examine the program effect after 1991, since the sample may include people who benefited from the child health interventions or smaller family sizes as children, and this is not the topic of this paper.

\subsection{Data Sources}

The Matlab Health and Demographic Surveillance System contains individual-level, prospectively observed data on in- and out-migration, births, deaths, and marriages of all people living in the study site. The migration information also includes information on type of migration (domestic or international). These data were collected at least monthly during the study period by community health workers. ${ }^{6}$ When a migrant returns to the study area, they are assigned the same identification number they had when they left allowing for easy tracking of people in and out of the study site, and we link the monthly in and out migration data to determine migration status. This capturing of returns migrants allows us to model the flow of out-migrants as well as the stock of out-migrants.

There are a number of issues with the demographic surveillance data prior to 1979. First, the out-migration data are not comparable before and after 1979 due to a change in the number of villages covered by the demographic surveillance system. ${ }^{7}$ Second, the data on migration type is only available for the entire study site starting in 1979. And finally, there is concern about the quality of the earlier data (Chowdhury et al. 1981). ${ }^{8}$ To overcome these issues we use data from 1979-91.

Unfortunately, migration data is not complete for the study area in 1982 . The migration rate drops by a third between 1981 and 1982, then increases by a third between 1982 and $1983 .{ }^{9}$ As a

\footnotetext{
${ }^{6}$ Internal migration data (i.e. moves anywhere in the treatment or comparison area) is available starting in 1982.

${ }^{7}$ Due to the extra burden of the MCH-FP program, the number of villages in the study site (and hence the demographic surveillance system) was reduced by about $35 \%$ in October 1978. Prior to the change, movements between the villages that were retained and those that were dropped were internal moves and not recorded. However, after October 1978 movements between the areas would be coded as out-migrations.

${ }^{8}$ Migration in 1975 and 1976 were unusual years due to a severe famine throughout Bangladesh so are probably not good baseline years. There are also some data quality issues with the migration data prior to 1978 probably due to the disruptions resulting from the famine, and lost migration records due to degradation of the paper files while in storage.

${ }^{9}$ While this problem in the data is recognized by ICDDR,B, it is not clear why there are missing migration records in 1982. It could be due to households in the study site being renumbered that year for the census, and perhaps the start of the 6 months window for which migration is counted being adjusted to the start date of the census. This
} 
result, we exclude data from 1982 from our sample.

ICDDR,B collected periodic "census" data on all individuals in the study site. The 1974 and 1982 censuses provide information on household location and composition, education, marriage status, basic assets, and type of occupation of the household head. Using individual or household identifiers, relevant variables from these census data are linked to the demographic surveillance data. ${ }^{10}$ The 1974 census data is used to identify individual MCH-FP treatment status (section 3.2), to control for preprogram characteristics, to test if 1974 preprogram characteristics are similar between the treatment and comparison area. The 1982 census provides data on land ownership used in the baseline characteristics since it is not available in $1974 .^{11}$

\subsection{Defining the Intent-to-treat Indicator}

The village of residence determines program eligibility. Current village of residence could be endogenous if people moved into the treatment area to benefit from the program. To avoid this possible endogeneity, we use village of residence prior to the start of the program to assign a person an intent-to-treat status and create the binary treatment variable (referred to as $T$ in the tables). For those people who link directly back to the 1974 census, we use the village of residence in 1974 to assign treatment status. For those who migrated into the study area after the 1974 census, but before the start of the program, we use their village of residence when they first moved into the study area.

\subsection{Sample Age Restrictions}

We restrict the sample to women age 25-44 and men age 30-49 in order to focus on men and women who are most likely to be married and have children under age five. This restriction serves two purposes. First, this is the group of people most likely to benefit from the MCH-FP program, and second, it allows us to focus on labor migration rather than marriage migration, as most migration for women is for marriage. ${ }^{12} \mathrm{We}$ do not restrict the sample to people who are married since marriage itself may be endogenous. To determine the exact age cut offs, we examine data on the age of marriage for men and women, the percent of women with a child under the age of five, and the migration rate for the whole study site in 1979 in figure 3 . The black solid line in figure 3 shows the percent of women who had married by a given age. It demonstrates that by age 25 almost all women were married. Therefore, we use age 25 as the lower age bound to be sure we exclude migration for marriage. Most of these women also have a child under the age of five by this age. By age 44, women's fertility is low and the demand for contraceptives is likely quite low. In addition, less than 2 percent of women have a child under age 5 by this age, and less then one percent migrate. So, we don't include women after age 44 since the program is unlikely to affect these women. As shown on Figure 3 by the grey line, men marry later than women and most men are married by the age of 30 . Therefore, we focus on men aged $30-49$, since migration rates are very low by age 50 and few men are likely to have children

\footnotetext{
interpretation is supported by the fact that migration rates were depressed only during the first half of 1982 (the census was June 30), with a sudden rise in July before returning to usual levels.

${ }^{10}$ If we can't link the person directly to the 1974 census data, we try to link them via the household head of the first household they appear in in the dataset. We are unable to link less than 2 percent of the people in the dataset back to the 1974 census. For the regression analysis, we fill in any missing in the 1974 control variables with treatment or comparison area means. Results are similar if we exclude these observations.

${ }^{11}$ Using 1982 data is not optimal as it is not preprogram information, however, land ownership is a household level variable that remains fairly stable over time.

${ }^{12}$ Bangladesh is a patriarchal society in which women move into the household of the husband after marriage.
} 
under the age of five. ${ }^{13}$

As a falsification test, we examine a group of men aged 19-22 who are less likely to benefit from the MCH-FP program. We focus on this group for two reasons. First, as shown in figure 3 , the majority of these men are not married. Second, we want to identify a group of men who are old enough that they are likely to migrate on their own rather than with their parents. ${ }^{14,15}$

\subsection{Dependent Variables and Analytic Datasets}

Bangladesh is similar to many rural areas in lower-income countries in that it is primarily a migrant-sending area and there are few new-migrants to the area. However, high rates of outmigration from this heavily migrant-sending area are associated with high rates of return migration. As a result, the effect of the program on rates of out-migration may be negated over time by return migration. We therefore examine both the annual flow of out-migration and the cumulative stock of out-migration, or the share of individuals living outside the area in a given year.

We use the demographic surveillance data to construct two separate person-year-level datasets covering the years 1979-91 to represent the flow and stock of out-migration. To examine the annual flow of individuals migrating out of the study site we construct an annual repeated cross section of individuals in the sample age range (e.g. females 25-44 and males 30-49) that lived in the study site prior to the start of the program in 1977 conditional on being at risk of outmigration, or having not already migrated out of the study site or died. We construct binary indicators of out-migration by type of migration (domestic, international) and define a person to be an out-migrant if they moved outside the study site for that calendar year and is zero if they remained in the study area. ${ }^{16}$

To examine the stock of out-migrants, we follow a panel of individuals who were in the sample age range at any point during the 1979-91, but that lived in the study area at the end of 1978. ${ }^{17}$ Individuals only enter the analysis sample when they reach the minimum age for the sample in the current observation year (e.g. 25 for females and 30 for males). We use the migration data to create a binary variable that measures the stock of out-migrants and takes the value one if the panel individual lived outside the study area in a particular year and zero if they lived in the study area. If a person dies, all subsequent observations are set to missing. ${ }^{18}$

\subsection{Pattern of Migration}

Table 1 describes rates of out-migration to domestic and international destinations for the three main time periods. Rates are further disaggregated by religion of respondent in order to highlight the distinct patterns of migration affecting the majority Muslim and minority Hindu populations in the area. Rates of out-migration are fairly high even for our older sample at 2 to 3

\footnotetext{
${ }^{13}$ We do not display data on the percent of men with a child under age five since it is missing for many men due to the difficulty of linking children to their fathers in this time period. However, using the data that does exist shows that less than 4 percent of men age 50 have a child and there is a drop in the percent around age 49 .

${ }^{14}$ Results are not sensitive to the exact age cut off.

${ }^{15}$ While 19-22 year olds could move with their families, the vast majority of their moves, unlike those of younger or older men or same-age women, were solo moves for employment or schooling.

${ }^{16}$ An alternative way to describe the dataset is that we follow a panel of people who age in and out of the sample depending on their age in the current observation year, and whose out-migration status is set to missing if they had migrated out of the study prior to that calendar year and not returned, or had died.

${ }^{17}$ We also use a short census taken in late 1978 to determine who is living in the study area at the end of 1978.

${ }^{18}$ Deaths after migration is not recorded, but death rates are low for people in the sample age ranges.
} 
percent per year. However, the vast majority of migration, particularly in earlier periods, was to domestic destinations. International migration flows were low and dominated by the Hindu minority. Between 1979-81, Hindus, who represent less than $15 \%$ of the study population, accounted for 90 of international moves for women $25-44$ and $50 \%$ for men $30-49$. This is a historical legacy of the partition of India, when Bangladesh (then East Pakistan) was created as a Muslim majority state with a sizable Hindu minority. There is a rise in international migration with the increase of guest worker migration to the Middle East and Southeast Asia in the 1980s, though much of this activity postdates the program. By contrast, domestic out-migration is dominated by Muslims, with rates of less than 0.25 percent for Hindus. Finally, the table also shows a limited number of observations missing destination type.

To account for the differences in domestic and international migration patterns between Hindus and Muslims we include individual year times religion controls and as a robustness check drop Hindus from the sample. We include separate results on international migration in the analysis, however, given the rates are so low, especially for women, we mainly focus on the effects of the program on domestic migration. However, we do present results also for outmigration, regardless of destination, in order to verify results are consistent with the inclusion of unknown destinations and international migrants.

\subsection{Trends in the Flow and Stock of Out Migration}

Figure $4 \mathrm{a}$ and $\mathrm{b}$ presents the trends in flow of domestic out-migration (left axis) and the stock of out-migration (right axis) from 1979-1991 for women aged 25-44 and men aged 30-49. Data for 1982 is not included due to the data issues discussed in section 3.1. These figures demonstrate that, in the early part of the program, 1979-81, the levels of out-migration flows were fairly similar between the treatment and comparison areas for both men and women. After 1981, however, there was a large increase in the flow of out migrants in the comparison area for these two groups. There was a similar increase in the internal migration rate in Bangladesh in general during this time period (Afsar 2003). However, the treatment area did not experience the same increase in migration rates as the comparison area. The difference between the two areas narrows after 1988. Taking into account the heavy flow of return migration, the trends in outmigrant stock suggest that more people from the comparison area remained outside the study area after 1983.

In figure 4c, we examine the flow of domestic out-migration for those less likely to be affected by the program, men aged 19-22 - the group of men we later use as a falsification test for the flow of out-migration. Migration rates are similar between the treatment and comparison area until 1986. Starting in 1987, the difference in migration rates between the treatment and comparison area increased for these men. This is likely a result of the Meghna-Dhonnogoda Irrigation project discussed in section 2.4 that was completed in 1987 and displaced people and changed migration patterns. This change in migration rates for the 19-22 year olds highlights the need to control for the embankment project.

\section{Estimation Strategy}

\subsection{Quasi-random Program Design}

The MCH-FP program assigned villages to treatment and comparison groups, but villages were not assigned randomly. Instead, the treatment and comparison areas are contiguous geographic areas (Figure 1), which were viewed as socially and economically similar and 
geographically insulated from outside influences at the time (Phillips et al. 1982). Assigning treatment status to geographic contiguous areas was used to reduce potential contamination of the comparison area from the family planning interventions (Huber and Khan 1979), and was also important for reducing spillovers from the positive externalities generated by vaccination. Past research shows that the treatment and comparison areas are similar with respect to potential targeting outcomes including rates of mortality and fertility (Koenig et al. 1990; Menken and Phillips 1990; Joshi and Schultz 2013). This is important since it means the program was not placed first in areas that had poor child health or high fertility. Barham (2012) also shows that most household preintervention characteristics are balanced, and that cognitive functioning was similar between the treatment and comparison area in 1996 for those whose cognitive functioning was not likely to have been affected by the program.

We use the 1974 census to test whether characteristics of females and males in our target age ranges in 1974 were similar. ${ }^{19}$ Table 2 presents means for the treatment and comparison group separately and the differences in means between the two group. We present the means for males and females together, but the results are similar if we separate the sexes. As well as reporting the statistical significance of the differences in means between the treatment and comparison areas, we examine the normalized differences in means (difference in the means divided by the standard deviation of the mean for the sample). The normalized difference provides an indication of the size of the differences in means, since small differences in means can be statistically significant with large sample sizes (Imbens and Wooldridge 2009). Normalized differences bigger than 0.25 standard deviations are generally thought to be substantial. Table 2 highlights that the differences in means are insignificant at the five percent level for all variables except years of education, religion, drinking water sources, and number of rooms per capita. With the exception of religion and drinking water sources, the normalized difference are less than 0.14 demonstrating that the differences that do exist are relatively small. The difference in tubewell access is large. The differences are the result of a government program, ${ }^{20}$ so do not reflect household income, propensity to drill a tubewell, or a household's concern about child health or potentially other unobservables that could be correlated with a person's propensity to migrate. These findings, together with previous results on fertility and mortality, strongly suggest that the two areas had very similar observable characteristics with the exception of religion and access to tubewell water. To account for the differences in baseline characteristics we include the observables interacted by the main time period dummies in the regressions to help control for any biases. In addition, as a robustness check we exclude Hindus from the analysis.

\subsection{Identification Strategy}

To identify the intent-to-treat (ITT) effect of the MCH-FP program on out-migration, we exploit variation in program implementation across location in the treatment versus comparison areas. In addition, we take advantage of the phasing-in of the interventions over time within the treatment area to examine the effect of the program for three main time periods: (1) 1979-81 period when family planning and some basic maternal health interventions were introduced; (2)

\footnotetext{
${ }^{19}$ The sample includes females age 25-44 and males 30-49 in the 1974 census. We look at this group to determine if the types of households adults in the relevant age groups come from are balanced prior to the program. Results are similar if we use 1974 characteristics for our actual sample.

${ }^{20}$ In 1968 the government of Bangladesh (then East Pakistan) set out a goal of installing one tubewell for every 200 people. With the support of the United Nations Children Fund, by 1978 over 300,000 tubewells had been sunk, about one for every 250 rural inhabitants (Black, 1986).
} 
1982-88 when the child health interventions were rolled out; and (3) 1989-91, the period when many of the program interventions became available through government services in the comparison area. Note, we do not include data for 1982 in the analysis due to data issues, so on the tables indicate the middle time period is from 1983-88.

We would also like to examine the ITT effect in a preprogram period to determine if migration rates are balanced at baseline, and if not, to control for those differences. Due to data restrictions, this is not possible. Instead, we examine both single and double difference estimates of the ITT effect, where we use the 1979-81 period, when only some of the program interventions had been introduced, as the baseline period for the double difference model. To the extent there are already program effects in the 1979-81 period, the double difference model will under-estimate the program effect.

\subsection{Empirical Specification}

We estimate the single difference ITT effect on the flow and stock of out migration using two different data sets as described in section 3.4 for person $i$ age $a$ in year $t$ from village $v$ using the linear probability model:

(1) $M_{\text {iatv }}=\beta_{0}+\beta_{1} T_{v 74} * Y_{t}^{79-81}+\beta_{2} T_{v 74} * Y_{t}^{83-88}+\beta_{3} T_{v 74} * Y_{t}^{89-91}+\delta_{t}+\lambda_{a}+\omega X+\varepsilon_{\text {iatv }}$,

where for the flow of out-migration $M$ takes on the value 1 if individual $i$ migrated out of the study site in year $t$ and is 0 otherwise, while for the stock of out-migration, $M$, takes on the value 1 if individual $i$ lived outside of the study site in year $t$ and is 0 otherwise. $T_{v 74}$ is a binary variable that takes on the value 1 if person $i$, or $i$ 's household, resided in a treatment village before the MCH-FP program started, and 0 if from the comparison area. The $Y^{x}$, $s$ are binary variables that indicate the three periods, $1979-81,1983-88$ and $1989-91$. So, $\beta_{1}-\beta_{3}$ are the single difference ITT effects for the respective time periods. Observation year fixed effects, $\delta_{t}$, are also included to control for changes over time that are common to both the treatment and comparison area, and age fixed effects, $\lambda_{a}$, to control for any age specific migration trends. $\mathbf{X}$ is a vector of individual, households or village controls. These vary depending on the specification but include individual (gender and religion) characteristics, Hindu time year fixed-effects, preprogram erosion and meghna location and embankment controls (see section 2.4 for a list of the controls), baseline household and household head characteristics presented in Table 2 interacted by the 3 time periods, and preprogram village fixed-effects to account for non-timing varying differences between villages. When preprogram village fixed effects are included, $\beta_{1}$ drops out of the model since this effect is absorbed by the preprogram village fixed effects. The error term is clustered at the village level to account for the likely intracluster and serial correlation, as well as, heteroskedasticity inherent in the linear probability model.

For the out-migration flow models, the $\beta$ 's indicate the difference in the probability of migration out of the study site between the treatment and comparison area for the three time periods. When multiplied by 100 the $\beta$ 's represent percentage point differences in the flow of out-migration between the treatment and comparison area. In contrast, for models examining the stock of out-migration, the $\beta$ 's when multiplied by 100 indicate the difference in the percent of individuals in the sample living outside the study site between the treatment and comparison area. For both models, the $\beta$ 's can be used to determine the double differences estimate in the latter two periods by subtracting $\beta_{1}$ from $\beta_{2}$ or $\beta_{3}$. 


\section{Program impacts}

\subsection{Intent-to-Treat Program Effects on Flow of Out-Migration}

The program effects for domestic and international out-migration flows are presented in table 3 and 4 for females aged 25-44 and men aged 30-49 in any given year. ${ }^{21,22}$ International migration rates are low, especially in the 1979-81 period so results should be interpreted with care, but are included to highlight the potential difference in patterns. All regressions include observation year and age fixed effects, Hindu dummy, and controls for if a person lived in an erosion or Meghna village at baseline. We include additional controls across columns 2-4 to help determine if differences in observables between the treatment and comparison area are biasing the results. The embankment controls are included in column 2 and should reduce the program effects. It is difficult to compare the magnitude of the coefficients across males and females because the base migration rates differ. So, in panel $\mathrm{B}$ we report the percent change in the probability of migration relative to the comparison group mean for the time period of interest. Panel C presents the p-value for the double difference estimator using the 1979-81 period as the base.

We first examine if there is a difference in the probability of domestic out-migration between the treatment and comparison area during the 1979-81 period. Columns 1-3 show that for domestic migration there are no statistically significant differences for any of the three groups or specifications, and that the magnitude of the differences are small; the probability of outmigration in the treatment compared to the comparison area is 4 percent lower for women, 1 percent higher for men aged 30-49, and 2 percent higher for men aged 19-22.

During the 1983-88 period, the ITT estimates show the probability of domestic out-migration is lower in the treatment area than in the comparison area for both females aged 25-44 and male aged 30-49 and that the difference is significant at the 1 percent level. The difference in the probability of out-migration between the experimental groups decline for both sexes between columns 1 and 2 with the introduction of the embankment controls as expected. Column 2 shows that with the inclusion of the embankment controls the difference in the probability of migration between the two areas was -0.0053 for females and -0.0057 for men. As shown in panel B, the represents a 17 and 19 percent lower out-migration rate in the treatment compared to the comparison area for women and men respectively. The program effect is similar, at 19 percent difference for both sexes, with the inclusion of preprogram characteristics interacted by the three time periods including access to tube well, and individual year times Hindu interactions. The similarity in the results with the inclusion of the base time period controls provides some evidence that any differences in preprogram characteristics, such as between religion and access to tube well water, are not biasing results. Lastly, the lower probability of migration due to the program is similar when village fixed-effects are included at 18 percent for females and 21 percent for males (column 4). ${ }^{23}$

By the 1989-91 period the program effects are lower and no longer statistically significant in any of the specifications for women. For men, they are not statistically significant once base

\footnotetext{
${ }^{21} \mathrm{We}$ also examined the heterogeneous effects of the program between those with some and no education and those with and without land but found no significant differences in the probability of domestic out-migration.

${ }^{22}$ Results for domestic migration are similar if all out-migrations with missing destination type are coded as domestic migration.

${ }^{23}$ Results are slightly higher when specific village time trends area also included. However, some of the trends are being estimated off relatively few observations.
} 
controls are included; they are marginally significant at the 10 percent level without the inclusion of the base controls. The fact the point estimates are lower is not surprising since there were improvements in the supply of government services in the comparison area during this time period.

Since we cannot control for pre-program differences in migration rates between the treatment and comparison areas, we provide more conservative double difference results using the 1979-81 periods as a "baseline". The difference in the means between the two later time periods and 1979-81 can be calculated using the single difference results. The double-difference results are similar to the single difference due to the limited effect of the program during the 1979-81 period. It is slightly lower for women during the $1983-88$ period at -0.0053 , or 17 percent, when base controls are included. The p-value on this difference is presented in panel $\mathrm{C}$ and shows that for both sexes double difference results for domestic migration for the 1983-88 period are still statistically significant at the 1 percent level.

We find no statistically significant results on international migration for either sex during the two latter time periods. There is a marginally statistically significant (at the 10 percent level) difference in migration rate between the two areas in the 1979-81 period. However, this should be interpreted with caution since international migration rates were low and the difference could be driven by the imbalance in religion between the treatment and comparison area at baseline. Despite this lack of program effect for international migration, the results for out migration to any destination, or all migration, still mimic the results for domestic migration. However, the larger difference in the probability of out-migration in the 1979-81 period for international migration means the double difference estimates are no longer statistically significant.

We perform a number of falsification and robustness checks on domestic migration. First, since the embankment project led to the destruction of the erosion villages, in column 5 of tables 3 and 4 we exclude any individual who lived in an erosion village since 1977 from the sample. The results are very similar to column 3 , which is not surprising since variables to control for the higher out-migration from this area are included in the embankment controls. Second, we examine the effect of the program on domestic migration for men aged 19-22 in column 8 of table 4. We expect there to be a much lower impact on this group since most were not married or had children so would not directly benefit from the program during these ages. There is no statistically significant program effect for any of the periods and the point estimates for domestic migration for the 1983-88 period is positive rather than negative. This provides some further confidence that the reduction in domestic out-migration flows due to the program during this time period for females aged 25-45 and males aged 30-49 is not likely a result of unobservable time-varying characteristics. Third, we run the results only on the Muslim population due to the imbalance at baseline in religion and again find similar results (results not reported). ${ }^{24}$ Finally, in case there is a difference in the probability of return migration between the two areas, for those who have more than one out-migration event, we restrict the analysis to the first event and again find similar results for both men and women (results not reported).

\subsection{Intent-to-Treat Program Effects on Migrant Stock}

Results in migrant stock presented in table 5 show that for females the pattern is similar to the flow of domestic out-migration for the 1983-88 period. With the inclusion of the base controls in column 2 , the stock of out-migrants was 1.4 percent lower in the treatment than in the

\footnotetext{
${ }^{24} \mathrm{We}$ also examined the effects on a cohort of females aged 25-44 and males aged 30-49 in 1978 rather than allowing people to age into the sample over the time period and found similar results.
} 
comparison area, though it is slightly higher with the inclusion of the village controls. This represents a percent change of 10 percent relative to the comparison group mean for the time period of interest (panel C). The percent change is 9 percent using a double difference model for column 2 or with the inclusion of village fixed-effects in column 3. In the 1989-91 period, the stock of out-migrants was 2.6 percent lower in the treatment than the comparison area, though this only represents an 8 percent change for both the single and double difference model and is marginally significant at the 10 percent level.

For males, the effect of the program on the stock of out-migrants in the 1983-88 or the 198991 period is small, less than half a percent, and is not statistically significant at the 5 percent level or above for any of the specifications. So while the results for out-migration flows showed that the program reduced the probability the males 30-49 migrated out of the treatment compared to the comparison area, the men in the comparison area eventually return.

\section{Conclusion}

This paper takes advantage of a highly effective health and family planning intervention, The Matlab Maternal and Child Health and Family Planning, in Bangladesh to provide new evidence on the impact of local benefit programs on out-migration. The program was quasi-randomly assigned in geographically contiguous areas. One important benefit of this block design is that our estimates are not likely to be biased by the large potential spillovers associated with the childhood vaccines provided by the program. We further take advantage of individual-level migration data to precisely estimate out-migration flows and stock and to address potential confounding factors.

The data has a few limitations, the most important of which is the lack of preprogram information on migration. To address this issue we use single and double difference estimators, where we use the early part of the program, 1979-91 when there was only partial roll-out of interventions, as a baseline for the double difference estimator. Program effects could be confounded by the introduction of the embankment project and the imbalance in religion and access to tubewell water at baseline. However, results are robust to the introduction of controls for the embankment project including the exclusion of villages that were submerged as a result of the construction, preprogram characteristics interacted by the three main time periods, and the exclusion of Hindus from the sample.

The findings show no effect of the program in the early period, 1979-81, but that during the most intensive years of program interventions, 1983-88, the flow of out-migration was about 19 percent lower for women and men of peak reproductive age living in the treatment area than the comparison area. Double difference results for women are slightly lower at 17 percent. Treatment-comparison differences in out-migration flows reduced and were no longer significant after supply of government health and family planning improved in the comparison area after 1988. As a falsification test, we demonstrate that the program had no effect on the mobility of young men aged 19-22 who were not likely to benefit from the program. These results on the flow of out-migration demonstrate that people do vote with their feet on the basis of access to services such as health and in this context the effects on the flow of migration are substantial.

Results on the out-migrant stock show more modest program effects, suggesting that return migration diminishes program effects over time. For women age $25-44$, the difference in outmigrant stock during the $1983-88$ period is only $9 \%$ and marginally significant, while there is no statistically significant program effect for males age 30-49. However, the results for men and women are not statistically different from each other. The program effect for women during 
1989-91 period was similar at 8 percent and still marginally significant. This finding illustrates the need to use individual-level data in studies of migration due to benefit programs in order to account for the effects of return migration. To the extent that the MCH-FP program encouraged individuals to remain in the study area, it may largely have affected those marginal migrants who were likely to return home anyway. When considering the role of migration in driving differential sample attrition bias in evaluation studies, it is also important to consider that differences, while important, may not endure over time and through the life course. 


\section{References}

Afsar, Rita. 2003. "Internal Migration and the Development Nexus: The Case of Bangladesh" http://www.eldis.org/vfile/upload/1/document/0903/Dhaka_CP_6.pdf.

Alam, M. G. Mahbub, Graeme Allinson, Frank Stagnitti, Atsushi Tanaka, and Martin Westbrooke. 2002. "Arsenic Contamination in Bangladesh Groundwater: A Major Environmental and Social Disaster." International Journal of Environmental Health Research, 12(3): 236-53.

Angelucci, Manuela. October 2011. "Conditional Cash Transfer Programs, Credit Constraints, and Migration." Unpublished.

Ardington, Cally, Anne Case, and Victoria Hosegood. 2009. "Labor Supply Response to Large Social Transfers: Longitudinal Evidence from South Africa," American Economic Journal: Applied Economics, 1(1), 22-48.

Barham, Tania. 2012 "The Effects of Child Health Interventions on Later Life Cognitive Functioning: Evidence from Matlab in Bangladesh," American Economic Journal: Applied Economics, 4(1), 245-73.

Behrman, Jere, Susan Parker, and Petra Todd. "Medium-Term Impacts of the Oportunidades Conditional Cash Transfer Program on Rural Youth in Mexico," in Poverty, Inequality and Policy in Latin America, eds. Stephan Klasen and Felicitas Nowak-Lehma (Cambridge, MA: MITpress, 2009).

Bhatia, Shushum, Wiley H. Mosley, Abu S. G. Faruque, and Jyotsnamoy Chakraborty. 1980. "The Matlab Family Planning-- Health Services Project," Studies in Family Planning, 11(6), 202-12.

Black, Maggie. 1986. The Children and the Nation: The Story of Unicef. UNICEF: New York.

Cebula, Richard J. 1979. "A Survey of the Literature on the Migration-Impact of State and Local Government Policies," Public Finance 34(1), 69-84.

Chen, N., P. Valente, and H. Zlotnik. 1998. What do we know about recent trends in urbanization? In Migration, Urbanization, and Development: New Directions and Issues, eds R. E. Bilsborrow, 59-88. New York: United Nations Population Fund \& Kluwer Academic Publishers.

Chowdhury, Mridul, Stan Becker, Abdur Razzaque, A.M. Sarder Kashem Shaikh, Lincoln Chen. May 1981. "Vital Events and Migration-1978," International Center for Diarrhoeal Disease Research Scientific Report No. 47.

Cleland, John, James F. Phillips, Sajeda Amin, and Golam M. Kamal. 1994. The Determinants of Reproductive Change in Bangladesh: Success in a Challenging Environment, Washington, DC: The International Bank for Reconstruction and Development/The World Bank.

Fauveau, Vincent. 1994. "Matlab: Women, Children and Health," Dhaka, Bangladesh: ICDDR,B.

Gelbach, Jonah. 2004. "The Life Cycle and State Benefits: How Low is the Bottom?” Journal of Political Economy, 112(5), 1091-1130.

Harris, J. and Michael Todaro. 1970. "Migration, Unemployment and Development: A TwoSector Analysis," American Economic Review 60(1), 126-142. 
Health and Demographic Surveillance System (HDSS). 2007. Registration of Health and Demographic Events 2005. Volume Thirty Nine. Scientific Report No. 97 - February 2007, Dhaka: ICDDR,B.

Huber, Douglas H., and Atiqur Rahman Khan. 1979. "Contraceptive Distribution in Bangladesh Villages: The Initial Impact," Studies in Family Planning, 10(8-9), 246-53.

Imbens, Guido W., and Jeffrey M. Wooldridge. 2009. "Recent Developments in Econometrics of Program Evaluation," Journal of Economic Literature, 47(1), 5-86.

Joshi, Shareen, and T. Paul Schultz. 2013. "Family Planning and Women's and Children's Health: Long-Term Consequences of an Outreach Program in Matlab, Bangladesh," Demography, 50(1), 149-180.

Khan, M. Mahmud, and Richard A. Yoder. 1998. "Expanded Program on Immunization in Bangladesh: Cost, Cost-Effectiveness and Financing Estimates," Partnerships for Health Reform Technical Report No. 24, http://www.path.org/vaccineresources/files/AbtPNACH278.pdf.

Koenig, Michael A., Mehrab Ali Khan, Bogdan Wojtyniak, John D. Clemens, Jyotsnamoy. Chakraborty, Vincent. Fauveau, James. F. Phillips, J. Akbar, and U. S. Barua. 1990. "Impact of Measles Vaccination on Childhood Mortality in Rural Bangladesh," Bulletin of the World Health Organization, 68(4), 441-47.

Koenig, Michael A., Vincent Fauveau, and Bogdan Wojtyniak. 1991. "Mortality Reductions from Health Interventions: The Case of Immunization in Bangladesh," Population and Development Review, 17(1), 87-104.

Kuhn, Randall. 2003. "Identities in Motion: Social Exchange Networks and Rural-Urban Migration in Bangladesh," Contributions to Indian Sociology 37, 311-337.

Kuhn, Randall. 2011. Testing a Model of Family and Individual Migration from a Rural Area of Bangladesh. Unpublished.

McKinnish, Terra. 2005. "Importing the Poor: Welfare Magnetism and Cross-Boarder Welfare Migration," Journal of Human Resources, 40(1), 55-76.

McKinnish, Terra. 2007. "Welfare-Induced Migration at State Borders: New Evidence from Micro-Data," Journal of Public Economics, 91(3-4),437-450.

Menken, Jane, and James F. Phillips. 1990. "Population Change in a Rural Area of Bangladesh, 1967-87," Annals of the American Academy of Political and Social Science, 510, 87-101.

Mobarak, A.M. R. Kuhn, and C. Peters. "Consanguinity and Other Marriage Market Effects of a Wealth Shock in Rural Bangladesh," Demography, forthcoming.

Moffitt, Robert. 1992. "Incentive Effects of the U.S. Welfare System: A Review," Journal of Economic Literature, 30(1), 1-61.

National Research Council (NRC). 2003. Cities Transformed: Demographic Change and Its Implications in the Developing World. Panel on Population on Urban Population Dynamics, M. R. Montgomery, R. Stren, B. Cohen, and H. E. Reed. Committee on Population, Davison of Behavioral and Social Sciences and Education. Washington, D.C.: The National Academies Press.

Phillips, James F., Wayne S. Stinson, Shushum Bhatia, Makhlisur Rahman, and Jyotsnamoy Chakraborty. 1982. "The Demographic Impact of the Family Planning--Health Services Project in Matlab, Bangladesh," Studies in Family Planning, 13(5), 131-40.

Phillips, James F., Ruth Simmons, Jyotsnamoy Chakraborty, and A. I. Chowdhury. 1984. "Integrating Health Services into an MCH-FP Program: Lessons from Matlab, Bangladesh," Studies in Family Planning, 15(4), 153-61. 
Phillips, James F. Tanya C. Jones, Frank K. Nyonator, Shruti Ravikuma. 2003. Evidence-Based Development of Health and Family Planning Programs in Bangladesh and Ghana.

Population Research Division Working Paper No. 175, Population Council, New York.

Rahman, M., W.H. Mosely, A.R. Khan, A. I. Chowdhury, and J. Chakraborty. 1980.

"Contraceptive Distribution in Bangladesh: Some Lessons Learned," Studies in Family Planning, 11(6), 191-201.

Sjaastad, Larry A. 1962. "The Costs and Returns of Human Migration," Journal of Political Economy, 70(5), 80-93.

Stark, Oded and David E. Bloom. 1985. "The New Economics of Labor Migration," American Economic Review, 75(2), 173-178.

Stark, Oded and David Levhari. 1982. "On Migration and Risk in LDCs," Economic Development and Cultural Change, 31(1), 191-196.

Stecklov, Guy, Paul Winters, Marco Stampini, Benjamin Davis. 2005. "Do Conditional Cash Transfers Influence Migration? A Study Using Experimental Data from the Mexican PROGRESA Program," Demography, 42(4), 769-790.

Strong, Michael. A. and S.F. Minkin. 1992. The demographic, health, and nutritional impacts of the Meghna-Dhonagoda embankment. Bangladesh Flood Action Plan FAP 16 Environmental Study, Special Studies Program). Dhaka, Bangladesh, and Arlington, VA: ICDDR,B and ISPAN.

Van Ginneken J, R Bairagi, Ad Francisco, AM Sarder, P Vaughan. 1998. Health and demographic surveillance in Matlab: past, present and future. Dhaka, Bangladesh: Public Health Division, International Centre for Diarrhoeal Disease Research.

Winters, Paul, Guy Stecklov, Jessica Todd. Sept. 2006. "The Impact of Conditional Cash Transfers on Household Composition, Fertility, and Migration in Central America" Unpublished. 
Tables and Figures

Figure 1: Map of Matlab Study Area

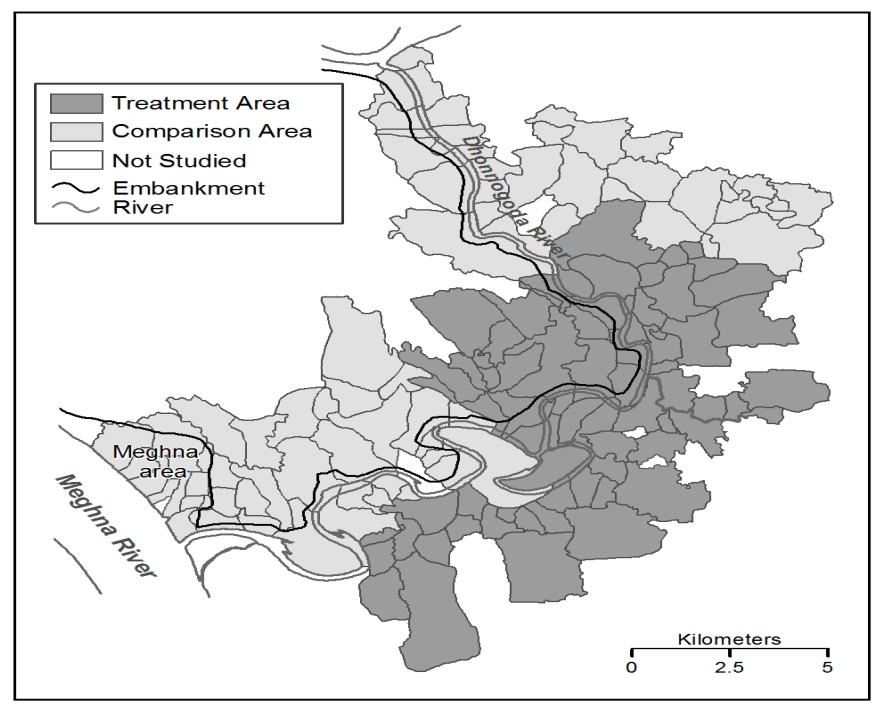

Figure 2: Trends in Contraceptive Prevalence Rate (CPR) and Measles Vaccination Rates (MVR) for Children 12-59 Months by Calendar Year

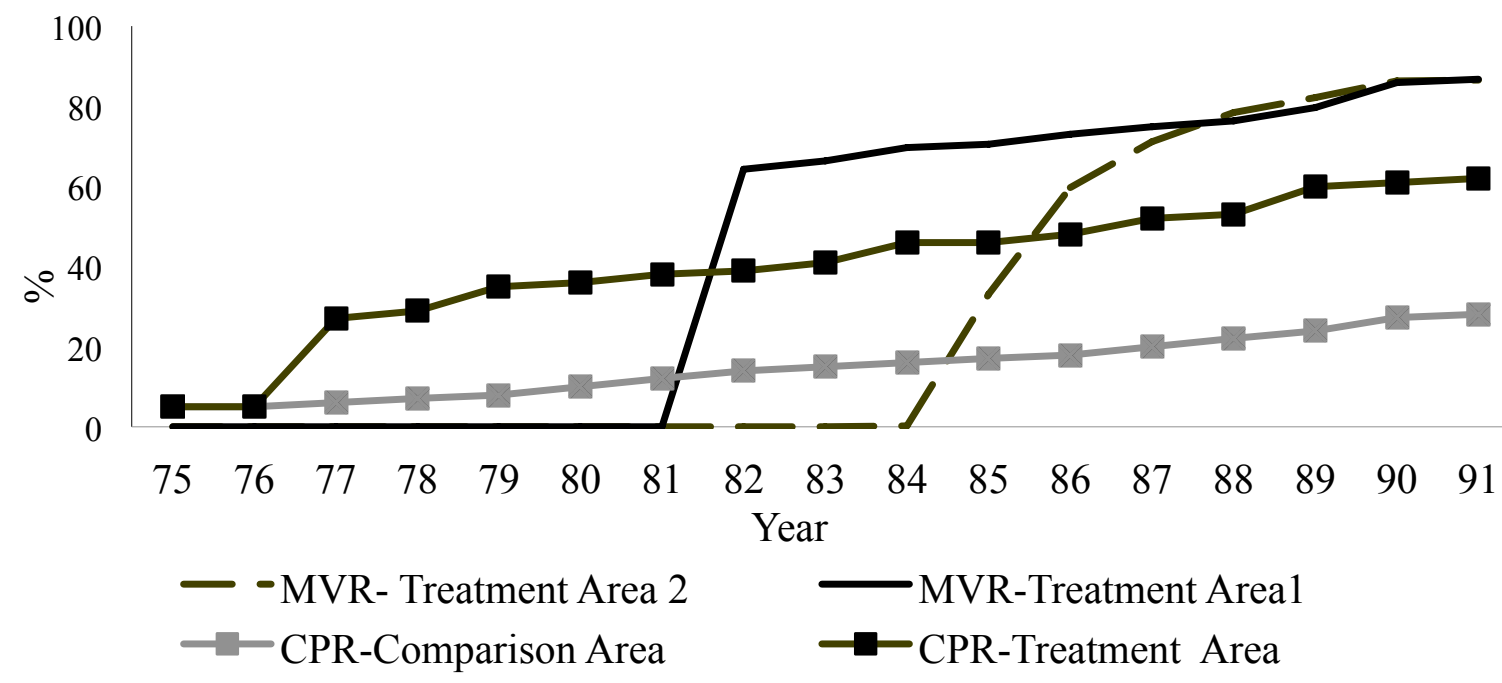

Source: Contraceptive use data from van Ginniken et. al. 1998; Measles vaccination data from ICCDR,B Record Keeping System. 
Figure 3: Age Patterns of Migration, Marriage and Childbearing in 1979

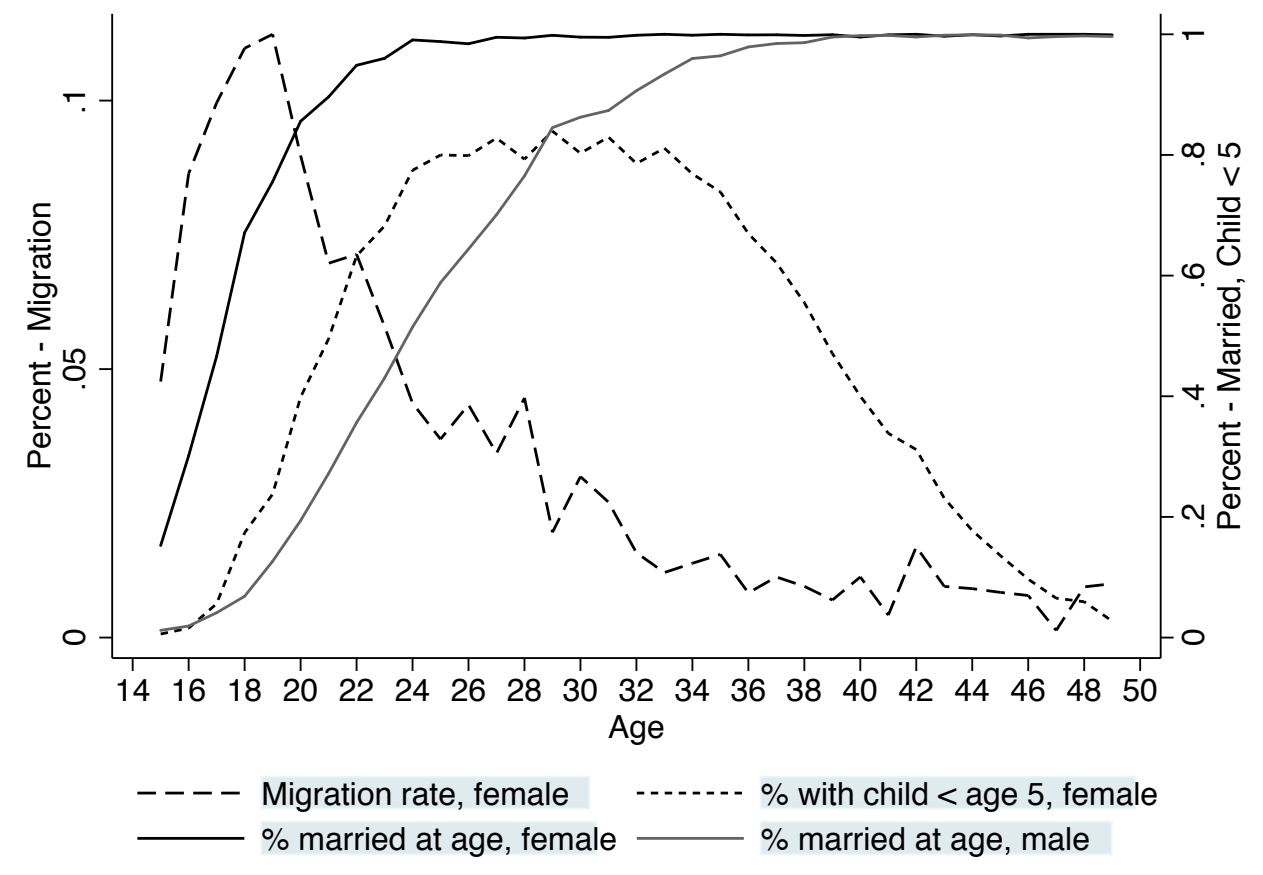


Figure 4a: Trends in Domestic Out Migration Rates for Females 25-44

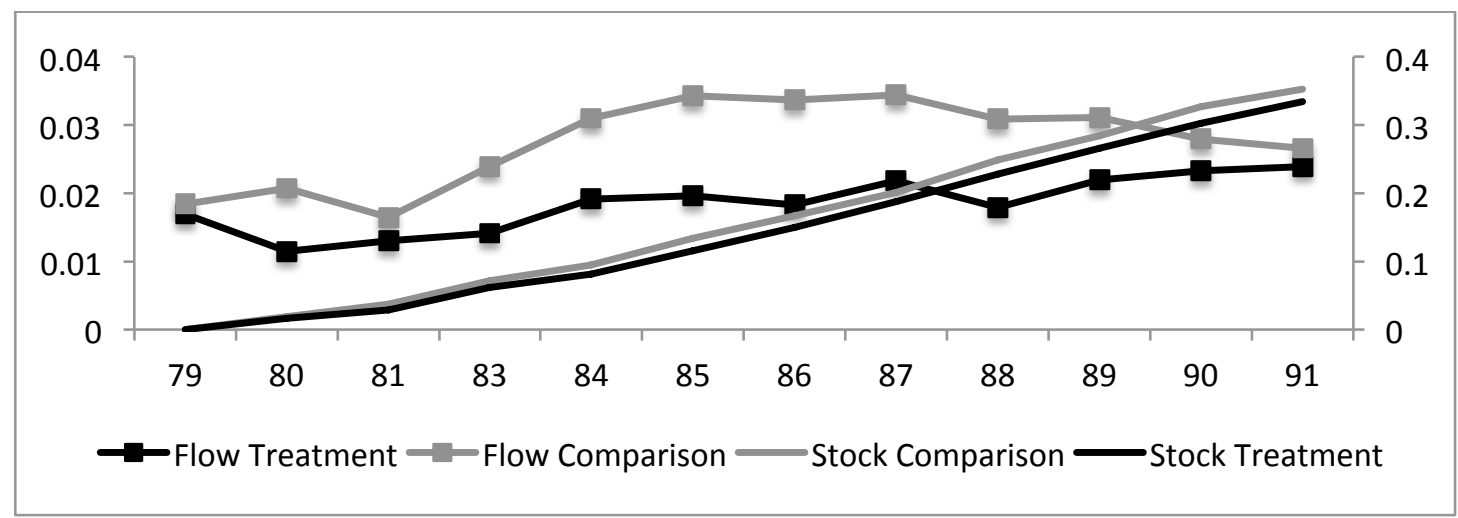

Figure 4b: Trends in Domestic Out Migration Rates for Males 30-49

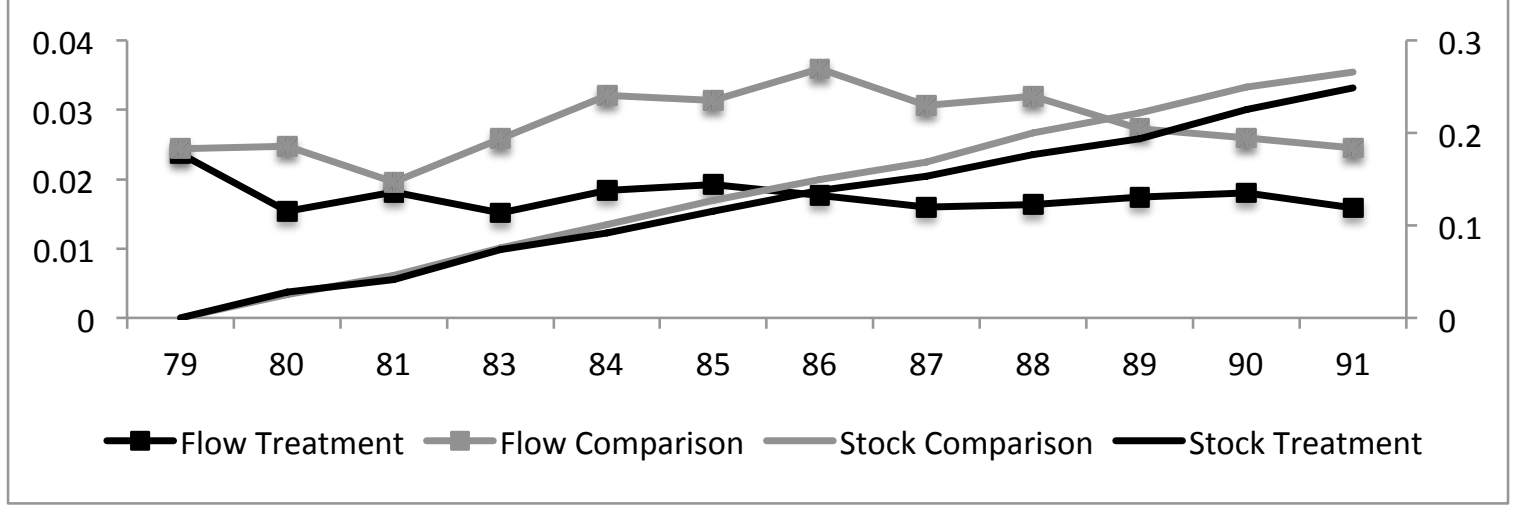

Figure 4c: Trends in Domestic Out Migration Rates for Males 19-22

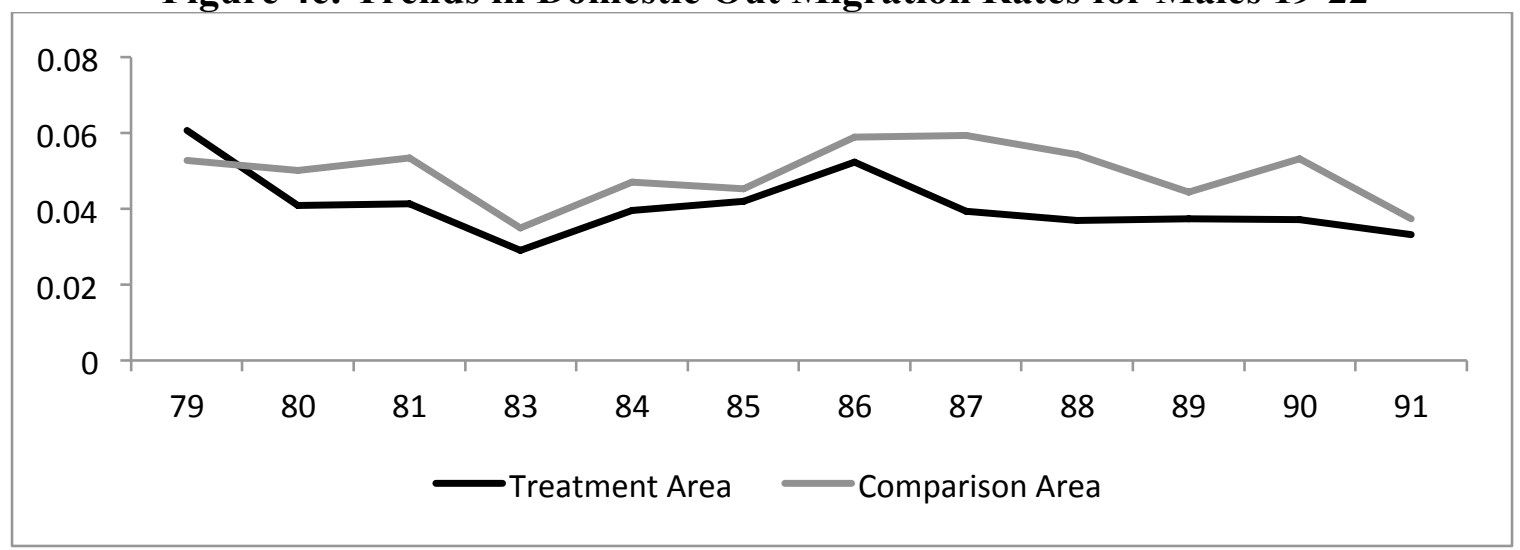

Notes: 1982 data not included due to issues with the data for that year. 
Table 1: Migration Rates by Destination and Time Period, in Percent

\begin{tabular}{|c|c|c|c|c|c|c|c|c|c|}
\hline & \multicolumn{3}{|c|}{ 1979-1981 } & \multicolumn{3}{|c|}{$1983-1988$} & \multicolumn{3}{|c|}{ 1989-1991 } \\
\hline & All & Muslim & Hindu & All & Muslim & Hindu & All & Muslim & Hindu \\
\hline \multicolumn{10}{|c|}{ Panel A: Females 25-44 } \\
\hline Domestic & 1.70 & 1.54 & 0.16 & 2.43 & 2.20 & 0.23 & 2.57 & 2.35 & 0.22 \\
\hline International & 0.14 & 0.02 & 0.12 & 0.25 & 0.03 & 0.23 & 0.42 & 0.01 & 0.40 \\
\hline Unknown & 0.02 & 0.02 & 0.00 & 0.00 & 0.00 & 0.00 & 0.08 & 0.01 & 0.07 \\
\hline \multicolumn{10}{|c|}{ Panel B: Males 30-49 } \\
\hline Domestic & 2.20 & 2.00 & 0.19 & 2.35 & 2.15 & 0.21 & 2.13 & 1.96 & 0.17 \\
\hline International & 0.24 & 0.12 & 0.12 & 0.61 & 0.36 & 0.25 & 1.18 & 0.70 & 0.47 \\
\hline Unknown & 0.04 & 0.04 & 0.00 & 0.01 & 0.01 & 0.00 & 0.06 & 0.00 & 0.06 \\
\hline
\end{tabular}

Notes: 1982 data not included due to issues with the data for that year. 
Table 2: 1974 Characteristics for Females aged 25-44 and Males aged 30-49 in 1974

\begin{tabular}{|c|c|c|c|c|c|c|c|c|c|}
\hline & \multicolumn{3}{|c|}{ Treatment Area } & \multicolumn{3}{|c|}{ Comparison Area } & \multicolumn{3}{|c|}{ Difference in Means } \\
\hline & Mean & $\mathrm{SE}$ & Obs & Mean & SE & Obs & Mean & $\begin{array}{c}\text { T- } \\
\text { stat }\end{array}$ & $\begin{array}{c}\text { Mean/ } \\
\text { SD }\end{array}$ \\
\hline \multicolumn{10}{|l|}{ Individual Characteristics } \\
\hline Years of education - females & 0.94 & $(0.06)$ & 9,246 & 0.75 & $(0.04)$ & 9,192 & 0.20 & 2.79 & 0.11 \\
\hline Years of education - males & 2.87 & $(0.11)$ & 7,918 & 2.43 & $(0.08)$ & 7,754 & 0.43 & 3.12 & 0.13 \\
\hline Married & 0.94 & $(0.00)$ & 17,237 & 0.93 & $(0.00)$ & 17,002 & -0.00 & 1.12 & 0.01 \\
\hline Muslim $(=1)$ & 0.78 & $(0.04)$ & 17,237 & 0.88 & $(0.03)$ & 17,002 & -0.10 & -1.98 & -0.26 \\
\hline \multicolumn{10}{|l|}{ Household Characteristics } \\
\hline Land in 1982 (in acres) & 1.05 & $(0.04)$ & 16,835 & 1.12 & $(0.05)$ & 16,302 & -0.07 & -1.19 & -0.04 \\
\hline Family size & 6.88 & $(0.06)$ & 17,215 & 6.77 & $(0.05)$ & 16,979 & 0.11 & 1.50 & 0.04 \\
\hline Owns a lamp (=1) & 0.63 & $(0.02)$ & 17,204 & 0.6 & $(0.01)$ & 16,966 & 0.03 & 1.07 & 0.06 \\
\hline Owns a watch $(=1)$ & 0.14 & $(0.01)$ & 17,204 & 0.13 & $(0.01)$ & 16,966 & 0.01 & 1.14 & 0.04 \\
\hline Owns a radio $(=1)$ & 0.08 & $(0.01)$ & 17,204 & 0.08 & $(0.00)$ & 16,966 & 0.01 & 0.77 & 0.02 \\
\hline Wall tin or tinmix $(=1)$ & 0.30 & $(0.01)$ & 17,053 & 0.30 & $(0.01)$ & 16,786 & 0.00 & -0.09 & 0.00 \\
\hline Tin roof $(=1)$ & 0.79 & $(0.01)$ & 17,065 & 0.8 & $(0.01)$ & 16,788 & -0.01 & -0.45 & -0.02 \\
\hline Latrine $(=1)$ & 0.79 & $(0.02)$ & 17,201 & 0.83 & $(0.03)$ & 16,964 & -0.04 & -1.10 & -0.09 \\
\hline Number of rooms per capita & 0.20 & $(0.00)$ & 17,215 & 0.20 & $(0.00)$ & 16,979 & 0.00 & 2.29 & 0.05 \\
\hline Number of cows & 1.30 & $(0.06)$ & 17,199 & 1.18 & $(0.04)$ & 16,966 & 0.12 & 1.64 & 0.07 \\
\hline Number of boats & 0.62 & $(0.03)$ & 17,202 & 0.64 & $(0.02)$ & 16,966 & -0.01 & -0.31 & -0.02 \\
\hline Drinking water, tubewell $(=1)$ & 0.34 & $(0.04)$ & 17,204 & 0.17 & $(0.02)$ & 16,955 & 0.17 & 4.27 & 0.40 \\
\hline Drinking water, $\operatorname{tank}(=1)$ & 0.37 & $(0.04)$ & 17,204 & 0.32 & $(0.03)$ & 16,955 & 0.05 & 1.09 & 0.11 \\
\hline Drinking water, other $(=1)$ & 0.28 & $(0.05)$ & 17,204 & 0.51 & $(0.04)$ & 16,955 & -0.23 & -3.83 & -0.46 \\
\hline $\mathrm{HH}$ age & 45.18 & $(0.24)$ & 17,200 & 44.73 & $(0.17)$ & 16,963 & 0.45 & 1.54 & 0.04 \\
\hline HH works in agriculture $(=1)$ & 0.58 & $(0.02)$ & 17,207 & 0.55 & $(0.02)$ & 16,968 & 0.03 & 0.90 & 0.06 \\
\hline $\mathrm{HH}$ works in fishing $(=1)$ & 0.08 & $(0.02)$ & 17,207 & 0.1 & $(0.01)$ & 16,968 & -0.02 & -0.86 & -0.07 \\
\hline HH spouse's age & 34.4 & $(0.20)$ & 15,703 & 34.16 & $(0.16)$ & 15,557 & 0.25 & 0.96 & 0.03 \\
\hline \multicolumn{10}{|c|}{ Percent of household members aged: } \\
\hline $0-4$ & 0.17 & $(0.00)$ & 17,215 & 0.17 & $(0.00)$ & 16,979 & 0.00 & 0.16 & 0.00 \\
\hline $5-9$ & 0.17 & $(0.00)$ & 17,215 & 0.17 & $(0.00)$ & 16,979 & 0.00 & 0.23 & 0.01 \\
\hline $10-15$ & 0.17 & $(0.00)$ & 17,215 & 0.17 & $(0.00)$ & 16,979 & -0.00 & -1.22 & -0.02 \\
\hline
\end{tabular}

Notes: Standard errors clustered at the village level. HH refers to household head. 
Table 3: ITT Effects on Flow of Out-Migration, Females 25-44

\begin{tabular}{|c|c|c|c|c|c|c|c|}
\hline & \multicolumn{5}{|c|}{ Domestic } & \multirow{2}{*}{$\begin{array}{c}\text { International } \\
(6)\end{array}$} & \multirow{2}{*}{$\begin{array}{l}\text { All } \\
(7) \\
\end{array}$} \\
\hline & $(1)$ & $(2)$ & (3) & $(4)$ & $(5)$ & & \\
\hline \multicolumn{8}{|c|}{ Panel A: Single differences } \\
\hline $\mathrm{T}^{*} 79-81$ & $\begin{array}{l}0.0007 \\
(0.002)\end{array}$ & $\begin{array}{c}-0.0007 \\
(0.001)\end{array}$ & $\begin{array}{c}-0.0005 \\
(0.002)\end{array}$ & & $\begin{array}{c}-0.0003 \\
(0.002)\end{array}$ & $\begin{array}{c}-0.0017 \\
(0.001)+\end{array}$ & $\begin{array}{c}-0.0024 \\
(0.002)\end{array}$ \\
\hline $\mathrm{T}^{*} 83-88$ & $\begin{array}{c}-0.0072 \\
(0.001)^{* *}\end{array}$ & $\begin{array}{c}-0.0053 \\
(0.001)^{* *}\end{array}$ & $\begin{array}{c}-0.0058 \\
(0.001)^{* *}\end{array}$ & $\begin{array}{c}-0.0056 \\
(0.002)^{* *}\end{array}$ & $\begin{array}{c}-0.0056 \\
(0.001)^{* *}\end{array}$ & $\begin{array}{l}0.0007 \\
(0.001)\end{array}$ & $\begin{array}{c}-0.0050 \\
(0.001)^{* *}\end{array}$ \\
\hline $\mathrm{T} * 89-91$ & $\begin{array}{r}-0.0012 \\
(0.002)\end{array}$ & $\begin{array}{r}-0.0025 \\
(0.002)\end{array}$ & $\begin{array}{r}-0.0026 \\
(0.002)\end{array}$ & $\begin{array}{c}-0.0024 \\
(0.002)\end{array}$ & $\begin{array}{c}-0.0028 \\
(0.002)\end{array}$ & $\begin{array}{l}0.0003 \\
(0.001)\end{array}$ & $\begin{array}{c}-0.0024 \\
(0.002)\end{array}$ \\
\hline \multicolumn{8}{|l|}{ Panel B: Percent changes } \\
\hline $\mathrm{T}^{*} 79-81$ & 4 & -4 & -3 & & -2 & -94 & -12 \\
\hline $\mathrm{T} * 83-88$ & -24 & -17 & -19 & -18 & -20 & 35 & -15 \\
\hline $\mathrm{T} * 89-91$ & -4 & -9 & -9 & -8 & -10 & 8 & -7 \\
\hline \multicolumn{8}{|c|}{ Panel C: P-value on the difference between the ITT effect in the last two periods and 79-81 } \\
\hline $83-88$ & 0.001 & 0.003 & 0.002 & & 0.007 & 0.017 & 0.143 \\
\hline $91-89$ & 0.389 & 0.395 & 0.335 & & 0.257 & 0.052 & 0.975 \\
\hline Embankment controls & $\mathrm{N}$ & Y & Y & Y & Y & Y & $\mathrm{Y}$ \\
\hline Base X period controls & $\mathrm{N}$ & $\mathrm{N}$ & $\mathrm{Y}$ & $\mathrm{Y}$ & $\mathrm{Y}$ & $\mathrm{Y}$ & $\mathrm{Y}$ \\
\hline Village fixed-effects & $\mathrm{N}$ & $\mathrm{N}$ & $\mathrm{N}$ & $\mathrm{Y}$ & $\mathrm{N}$ & $\mathrm{N}$ & $\mathrm{N}$ \\
\hline Drop erosion area & $\mathrm{N}$ & $\mathrm{N}$ & $\mathrm{N}$ & $\mathrm{N}$ & $\mathrm{Y}$ & $\mathrm{N}$ & $\mathrm{N}$ \\
\hline Adjusted $\mathrm{R}^{2}$ & 0.012 & 0.013 & 0.015 & 0.018 & 0.013 & 0.019 & 0.014 \\
\hline Observations & 234,661 & 234,661 & 234,661 & 234,661 & 227,735 & 229,960 & 235,352 \\
\hline
\end{tabular}


Table 4: ITT Effects on the Flow of Out-Migration, Males

\begin{tabular}{|c|c|c|c|c|c|c|c|c|c|}
\hline & \multicolumn{7}{|c|}{ Age 30-49 } & \multicolumn{2}{|c|}{ Age 19-22 } \\
\hline & \multicolumn{5}{|c|}{ Domestic } & \multirow{2}{*}{$\frac{\text { Int'l }}{(6)}$} & \multirow{2}{*}{$\begin{array}{l}\text { All } \\
(7)\end{array}$} & \multirow{2}{*}{$\begin{array}{c}\text { Domestic } \\
(8)\end{array}$} & \multirow{2}{*}{$\begin{array}{c}\text { Int'1 } \\
(9)\end{array}$} \\
\hline & $(1)$ & $(2)$ & $(3)$ & (4) & $(5)$ & & & & \\
\hline \multicolumn{10}{|c|}{ Panel A: Single differences } \\
\hline $\mathrm{T}^{*} 79-81$ & $\begin{array}{c}0.0020 \\
(0.002)\end{array}$ & $\begin{array}{c}0.0003 \\
(0.002)\end{array}$ & $\begin{array}{l}0.0002 \\
(0.002)\end{array}$ & & $\begin{array}{l}0.0002 \\
(0.002)\end{array}$ & $\begin{array}{c}-0.0018 \\
(0.001)^{+}\end{array}$ & $\begin{array}{c}-0.0012 \\
(0.002)\end{array}$ & $\begin{array}{c}0.0010 \\
(0.004)\end{array}$ & $\begin{array}{l}-0.0020 \\
(0.001)\end{array}$ \\
\hline $\mathrm{T} * 83-88$ & $\begin{array}{c}-0.0079 \\
(0.002)^{* *}\end{array}$ & $\begin{array}{c}-0.0057 \\
(0.002)^{* *}\end{array}$ & $\begin{array}{c}-0.0057 \\
(0.002)^{* *}\end{array}$ & $\begin{array}{c}-0.0062 \\
(0.002)^{* *}\end{array}$ & $\begin{array}{c}-0.0055 \\
(0.002)^{* *}\end{array}$ & $\begin{array}{l}0.0000 \\
(0.001)\end{array}$ & $\begin{array}{c}-0.0055 \\
(0.002)^{* *}\end{array}$ & $\begin{array}{l}0.0043 \\
(0.003)\end{array}$ & $\begin{array}{l}0.0017 \\
(0.002)\end{array}$ \\
\hline $\mathrm{T} * 89-91$ & $\begin{array}{c}-0.0038 \\
(0.002)^{*}\end{array}$ & $\begin{array}{c}-0.0039 \\
(0.002)+\end{array}$ & $\begin{array}{r}-0.0034 \\
(0.002)\end{array}$ & $\begin{array}{r}-0.0037 \\
(0.002)\end{array}$ & $\begin{array}{r}-0.0034 \\
(0.002)\end{array}$ & $\begin{array}{l}0.0014 \\
(0.001)\end{array}$ & $\begin{array}{r}-0.0021 \\
(0.003)\end{array}$ & $\begin{array}{c}0.0020 \\
(0.004)\end{array}$ & $\begin{array}{l}0.0017 \\
(0.003)\end{array}$ \\
\hline \multicolumn{10}{|c|}{ Panel B: Percent changes } \\
\hline $\mathrm{T}^{*} 79-81$ & 9 & 1 & 1 & & 1 & -64 & -5 & 2 & -51 \\
\hline $\mathrm{T}^{*} 83-88$ & -26 & -19 & -19 & -21 & -20 & 0 & -15 & 9 & 25 \\
\hline $\mathrm{T} * 89-91$ & -15 & -15 & -13 & -14 & -14 & 13 & -6 & 4 & 12 \\
\hline \multicolumn{10}{|c|}{ Panel C: P-value on the difference between the ITT effect in the last two periods and 79-81 } \\
\hline $83-88$ & 0.000 & 0.005 & 0.004 & & 0.007 & 0.185 & 0.085 & 0.477 & 0.075 \\
\hline $91-89$ & 0.019 & 0.073 & 0.120 & & 0.131 & 0.068 & 0.759 & 0.843 & 0.187 \\
\hline Embankment controls & $\mathrm{N}$ & $\mathrm{Y}$ & $\mathrm{Y}$ & $\mathrm{Y}$ & $\mathrm{Y}$ & Y & Y & Y & $\mathrm{Y}$ \\
\hline Base X period controls & $\mathrm{N}$ & $\mathrm{N}$ & $\mathrm{Y}$ & $\mathrm{Y}$ & $\mathrm{N}$ & Y & $\mathrm{Y}$ & Y & $\mathrm{Y}$ \\
\hline Village fixed-effects & $\mathrm{N}$ & $\mathrm{N}$ & $\mathrm{N}$ & $\mathrm{Y}$ & $\mathrm{N}$ & $\mathrm{N}$ & $\mathrm{N}$ & $\mathrm{N}$ & $\mathrm{N}$ \\
\hline Drop erosion area & $\mathrm{N}$ & $\mathrm{N}$ & $\mathrm{N}$ & $\mathrm{N}$ & $\mathrm{Y}$ & $\mathrm{N}$ & $\mathrm{N}$ & $\mathrm{N}$ & $\mathrm{N}$ \\
\hline Adjusted $\mathrm{R}^{2}$ & 0.007 & 0.008 & 0.011 & 0.014 & 0.009 & 0.008 & 0.010 & 0.011 & 0.012 \\
\hline Observations & 181,536 & 181,536 & 181,536 & 181,536 & 176,683 & 178,694 & 182,810 & 92,134 & 88,635 \\
\hline
\end{tabular}

Notes: Standard errors are in parentheses and clustered at the village level. "**" ,"*", or "+" indicates significant at the 1, 5, or 10 percent level. Data for 1982 is not included due to data issues All regressions include year and age fixed effects, Hindu dummy, and an indicator variable for living the erosion or Meghna village in 1974. Embankment controls are listed in section 2.4. Baseline time period controls include preprogram household characteristics from table 2 interacted by the three time periods, and year times Hindu fixed-effects. 
Table 5: ITT Effect on the Stock of Out-Migration

\begin{tabular}{|c|c|c|c|c|c|c|c|c|}
\hline & \multicolumn{4}{|c|}{ Females 25-44 } & \multicolumn{4}{|c|}{ Males 30-49 } \\
\hline & $(1)$ & $(2)$ & (3) & (4) & $(5)$ & $(6)$ & $(7)$ & $(8)$ \\
\hline \multicolumn{9}{|c|}{ Panel A: Single differences } \\
\hline $\mathrm{T}^{*} 79-81$ & $\begin{array}{c}-0.0052 \\
(0.005)\end{array}$ & $\begin{array}{c}-0.0016 \\
(0.004)\end{array}$ & & $\begin{array}{r}-0.0001 \\
(0.004)\end{array}$ & $\begin{array}{c}0.0011 \\
(0.004)\end{array}$ & $\begin{array}{c}0.0003 \\
(0.003)\end{array}$ & & $\begin{array}{c}0.0016 \\
(0.003)\end{array}$ \\
\hline $\mathrm{T} * 83-88$ & $\begin{array}{l}-0.0117 \\
(0.007)+\end{array}$ & $\begin{array}{l}-0.0141 \\
(0.007)^{*}\end{array}$ & $\begin{array}{l}-0.0129 \\
(0.007)+\end{array}$ & $\begin{array}{l}-0.0150 \\
(0.007)^{*}\end{array}$ & $\begin{array}{r}-0.0021 \\
(0.007)\end{array}$ & $\begin{array}{r}-0.0043 \\
(0.007)\end{array}$ & $\begin{array}{c}-0.0056 \\
(0.006)\end{array}$ & $\begin{array}{c}-0.0038 \\
(0.007)\end{array}$ \\
\hline $\mathrm{T} * 89-91$ & $\begin{array}{c}-0.0151 \\
(0.013)\end{array}$ & $\begin{array}{c}-0.0258 \\
(0.013)+\end{array}$ & $\begin{array}{c}-0.0245 \\
(0.013)+\end{array}$ & $\begin{array}{c}-0.0236 \\
(0.012)+\end{array}$ & $\begin{array}{c}0.0016 \\
(0.011)\end{array}$ & $\begin{array}{c}-0.0030 \\
(0.011)\end{array}$ & $\begin{array}{c}-0.0038 \\
(0.011)\end{array}$ & $\begin{array}{c}-0.0026 \\
(0.010)\end{array}$ \\
\hline \multicolumn{9}{|c|}{ Panel B: Percent Change } \\
\hline $\mathrm{T}^{*} 79-81$ & -25 & -8 & & -1 & 2 & -2 & & 7 \\
\hline $\mathrm{T}^{*} 83-88$ & -8 & -10 & -9 & -10 & 0 & -3 & -4 & -3 \\
\hline $\mathrm{T}^{*} 89-91$ & -5 & -8 & -8 & -8 & 2 & -1 & -2 & -1 \\
\hline \multicolumn{9}{|c|}{ Panel c: P-value on the difference between the ITT effect in the last two periods and 79-81 } \\
\hline $83-88$ & 0.281 & 0.041 & & 0.027 & 0.573 & 0.396 & & 0.362 \\
\hline $91-89$ & 0.440 & 0.059 & & 0.048 & 0.966 & 0.744 & & 0.673 \\
\hline Embankment controls & Y & Y & Y & Y & Y & Y & $\mathrm{Y}$ & $\mathrm{Y}$ \\
\hline Base X period controls & $\mathrm{N}$ & $\mathrm{Y}$ & $\mathrm{Y}$ & Y & $\mathrm{N}$ & Y & $\mathrm{Y}$ & $\mathrm{Y}$ \\
\hline Village fixed-effects & $\mathrm{N}$ & $\mathrm{N}$ & $\mathrm{Y}$ & $\mathrm{N}$ & $\mathrm{N}$ & $\mathrm{N}$ & $\mathrm{Y}$ & $\mathrm{N}$ \\
\hline Drop erosion area & $\mathrm{N}$ & $\mathrm{N}$ & $\mathrm{N}$ & $\mathrm{Y}$ & $\mathrm{N}$ & $\mathrm{N}$ & $\mathrm{N}$ & $\mathrm{Y}$ \\
\hline Adjusted $\mathrm{R}^{2}$ & 0.151 & 0.165 & 0.173 & 0.160 & 0.071 & 0.090 & 0.101 & 0.089 \\
\hline Observations & 300,093 & 300,093 & 300,093 & 265,624 & 221,190 & 221,190 & 221,190 & 200,106 \\
\hline
\end{tabular}

